Dedicated to the Aviation Club of Chicago
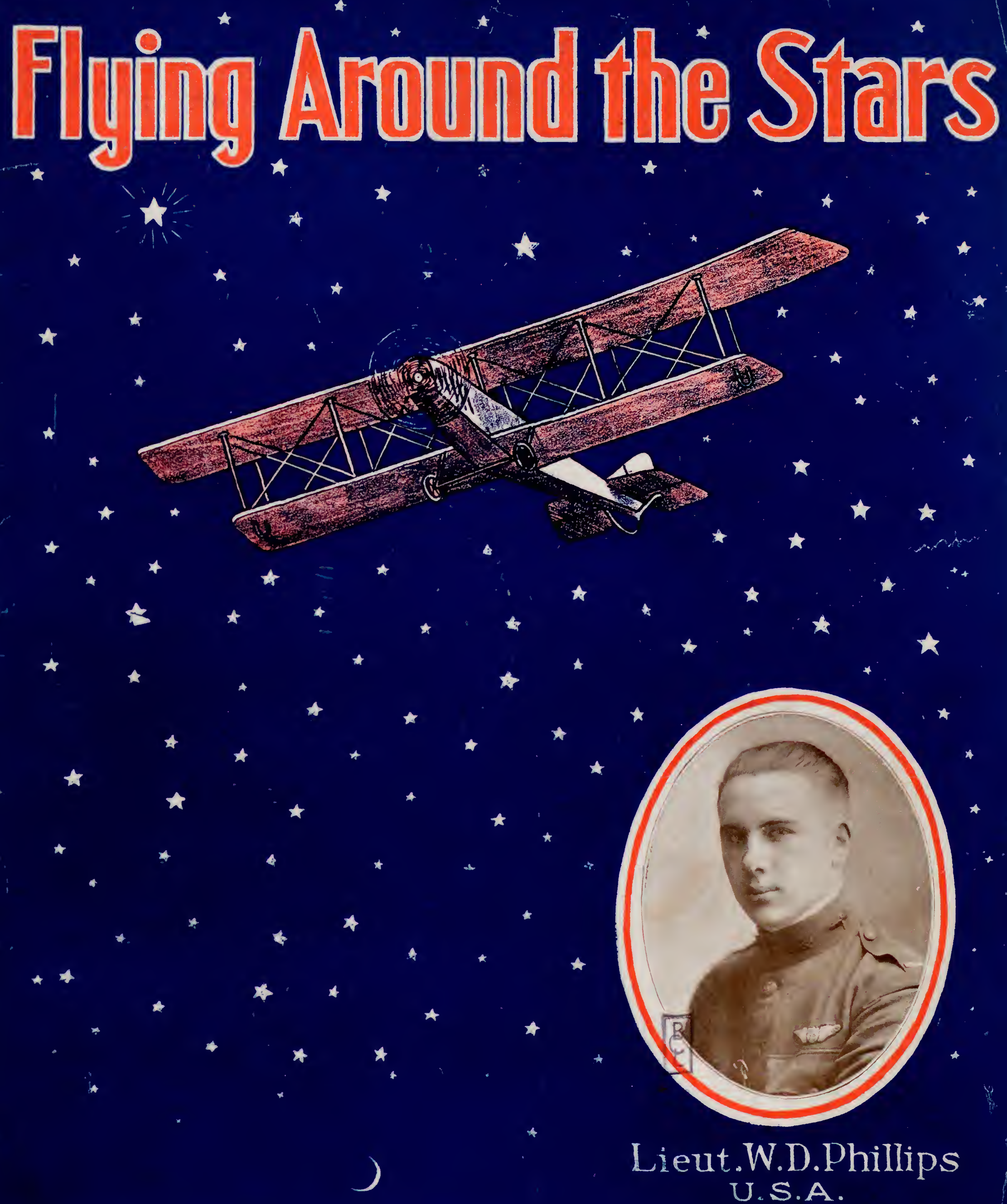


\section{Flying Around the Stars}

Words by

W. D. PHILLIPS

Music by
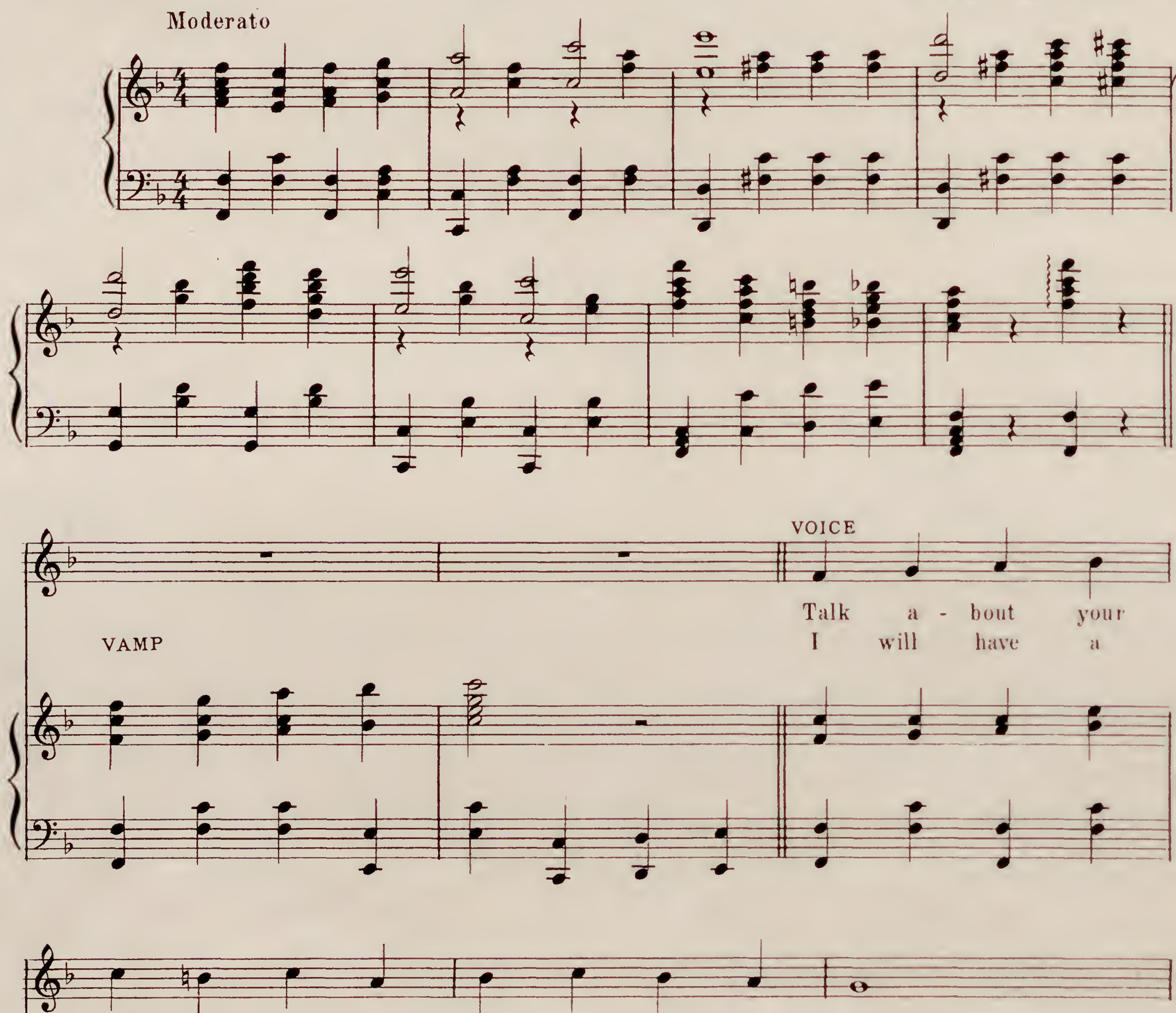
av - i - a - tors av - i - at - ing high. spread a - bout nine - hun - dred feet or more.

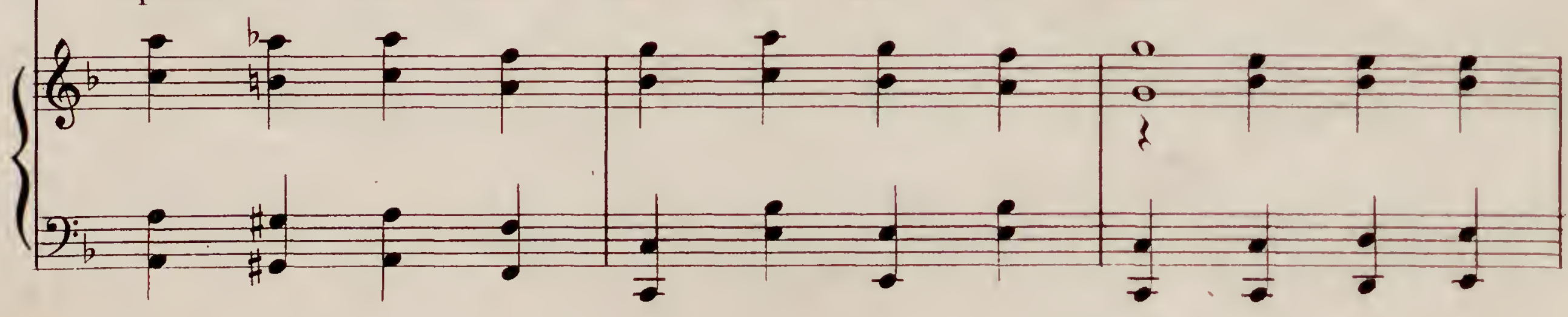

Copyright, MCMXXI, by W. D. Phillips, Robt.C. Bates and Lew Barton 

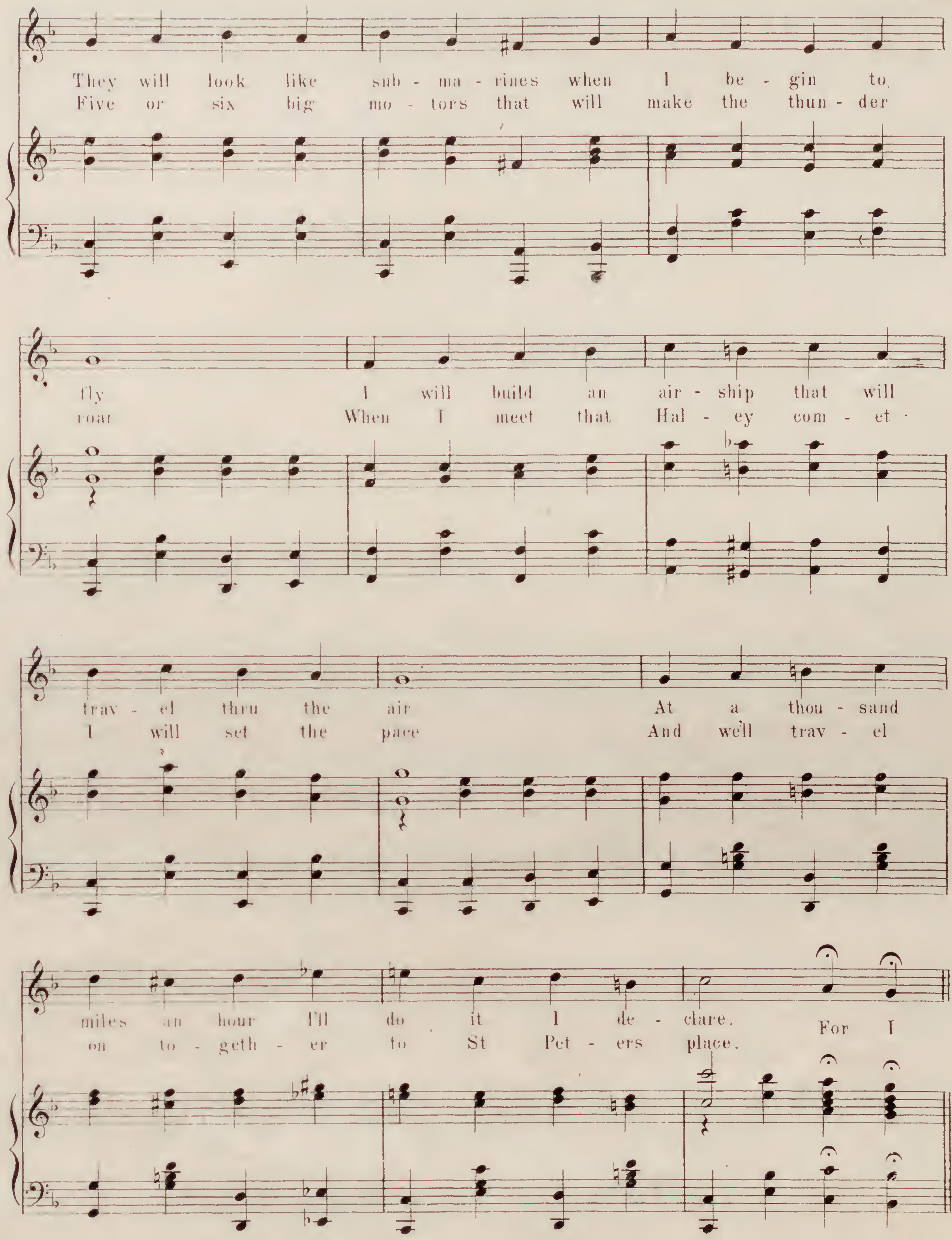
4

CHORUS Noderato

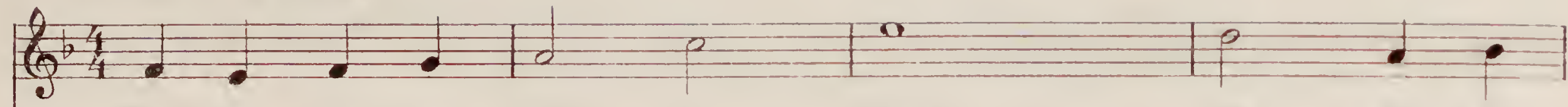

Want to take a trip to hear - - ell in an

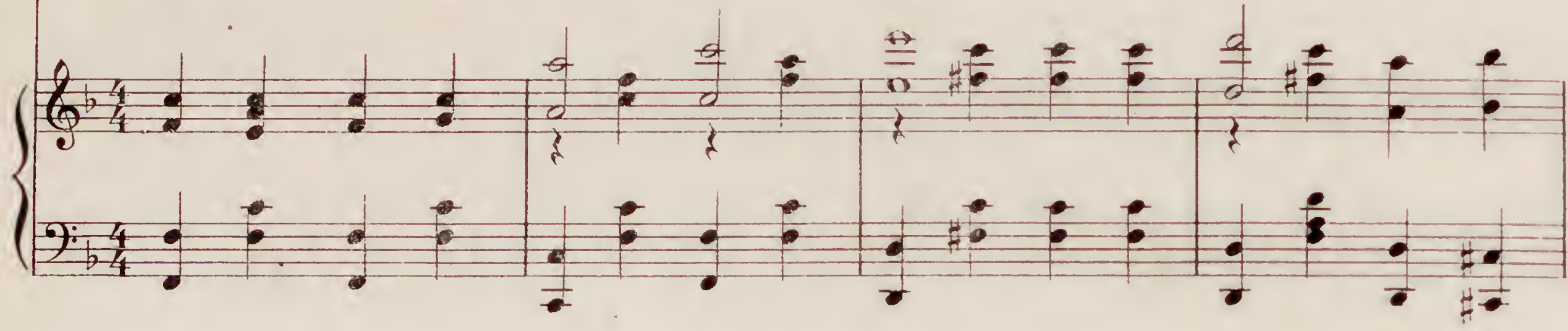

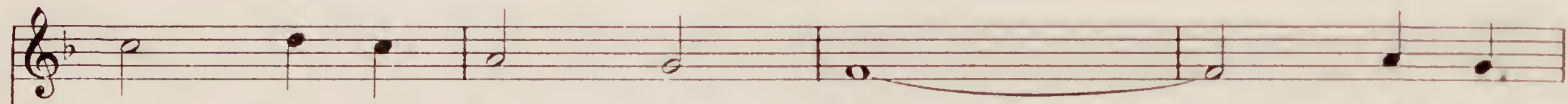

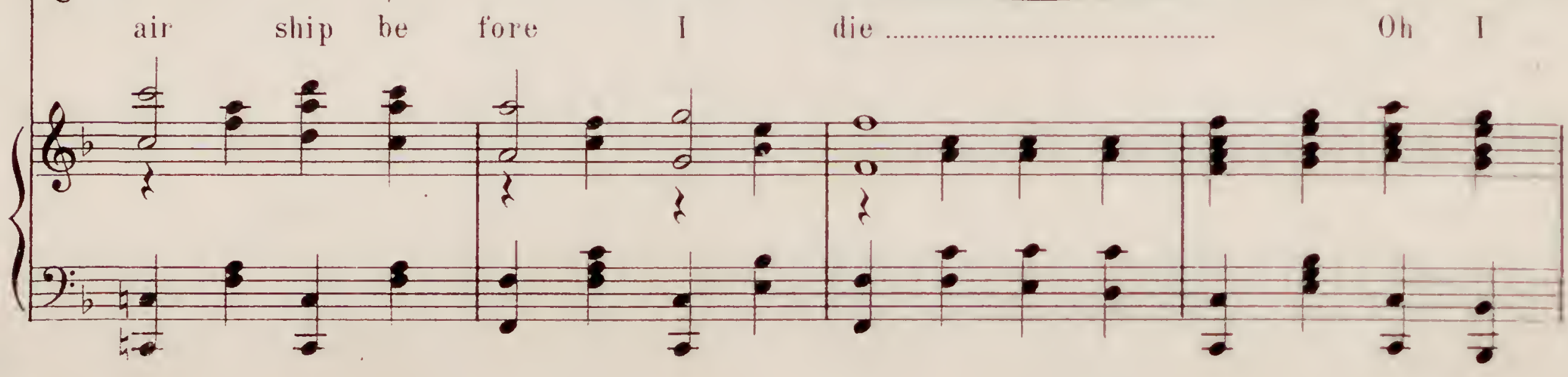

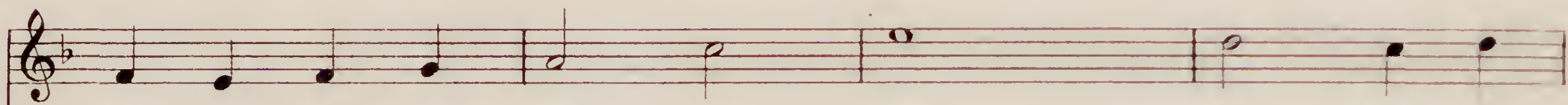
want to take a trip to hear - - en and to

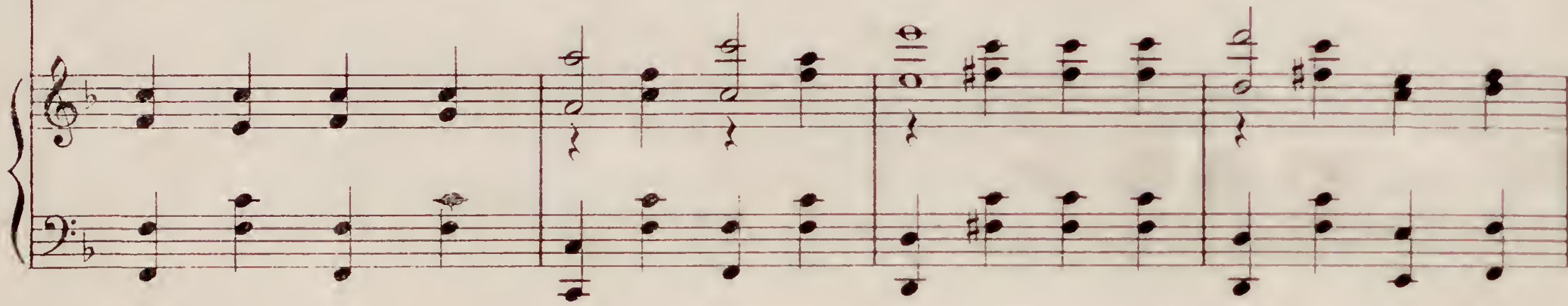

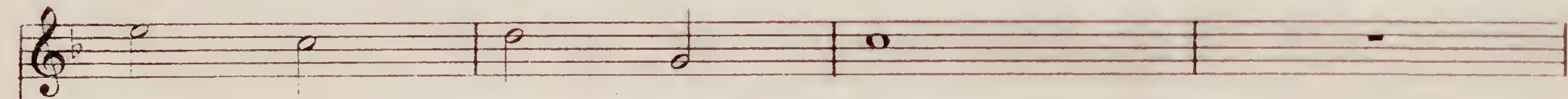

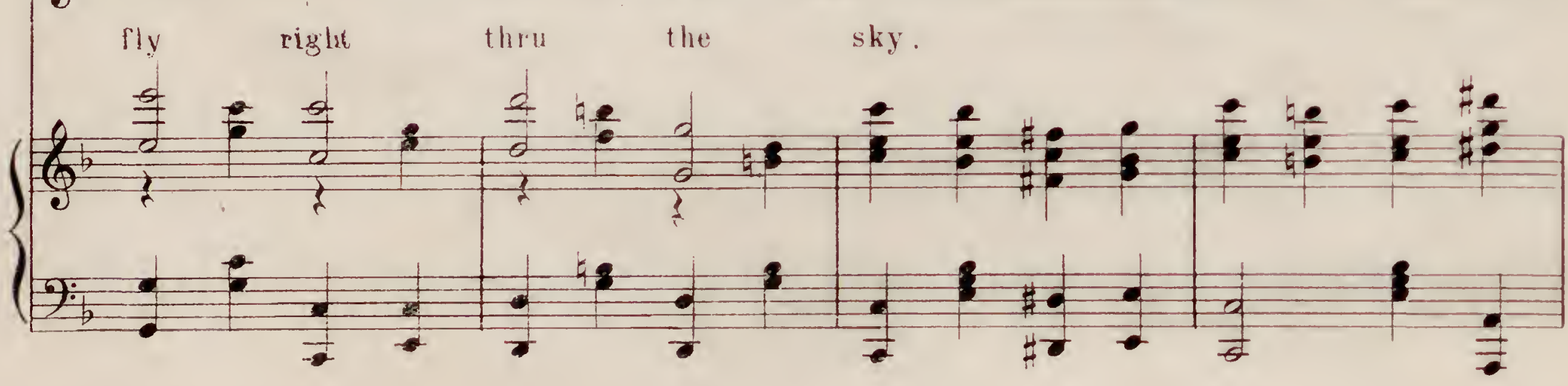




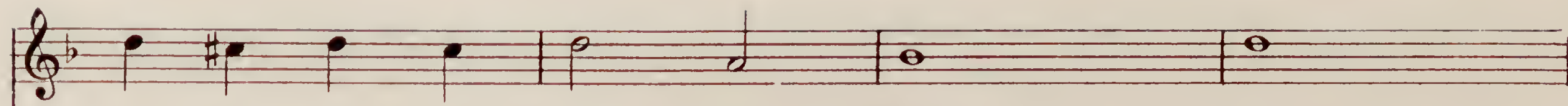
I will make a call on Ven - $u$ us

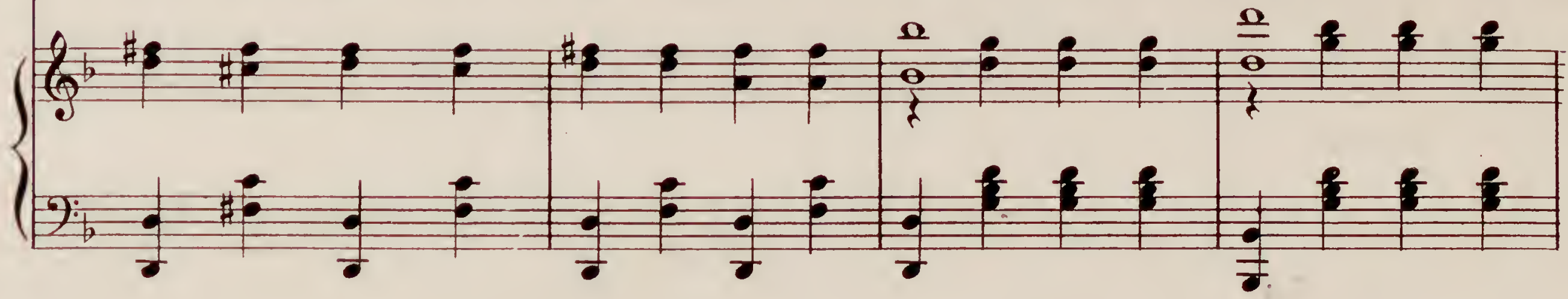

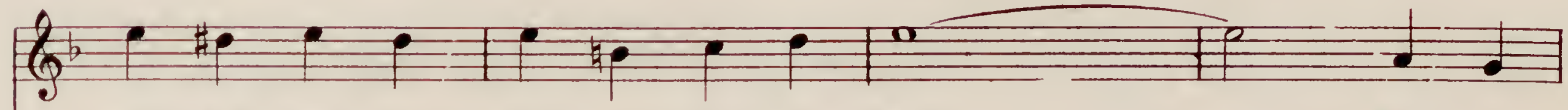
Stop and get my gas - 0 - line at Mars ....................................... For I
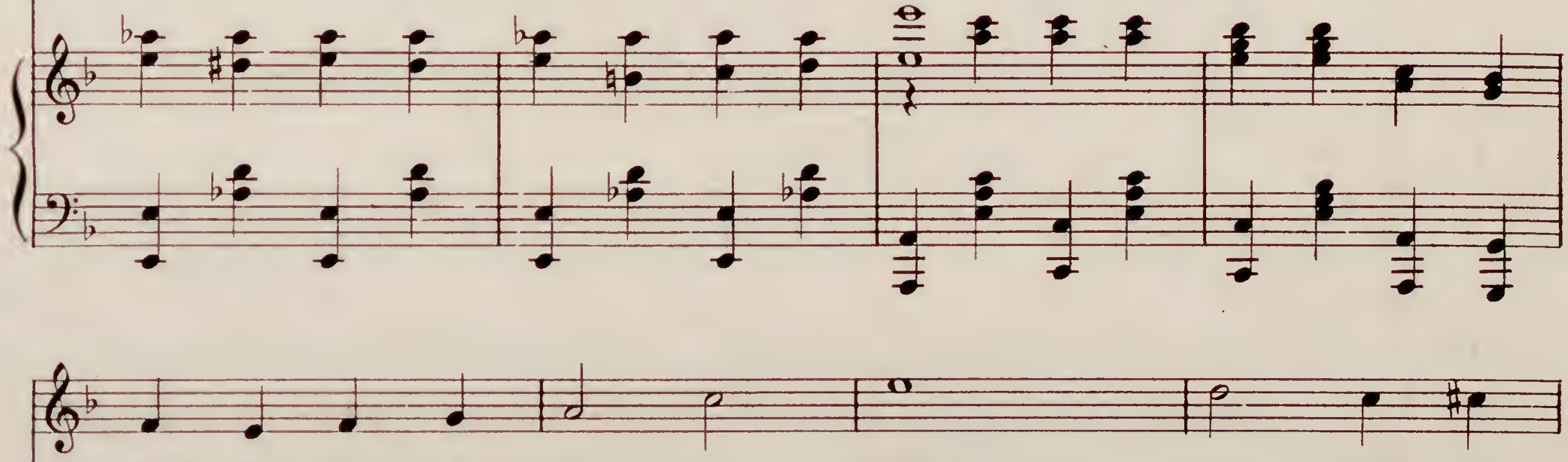
want to take a trip to heav - en and go
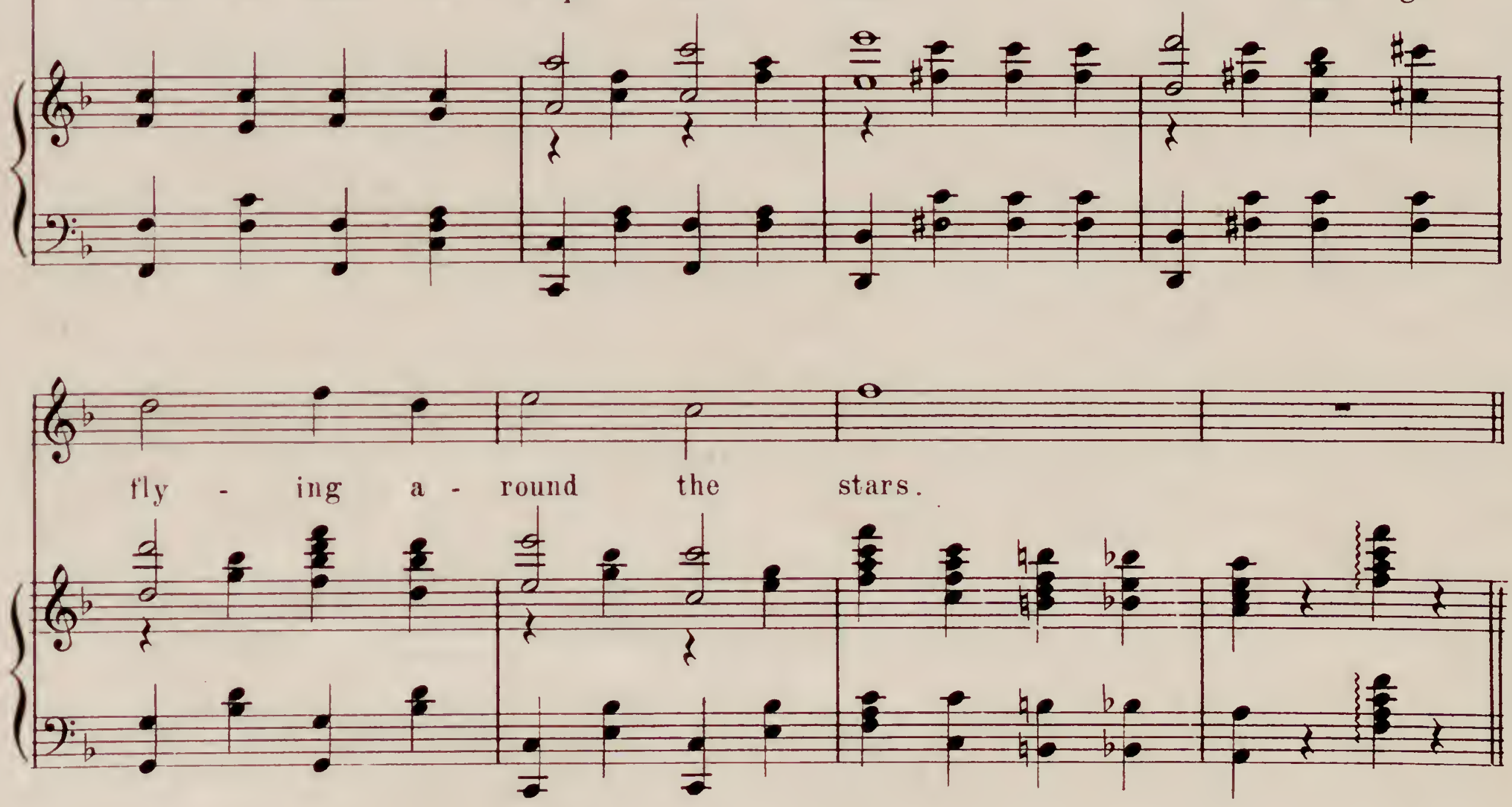
